\title{
Design a Fuzzy PID Controller Used for a LOS Guidance Law for Path Following of an Aircraft
}

\author{
Min-Seok Jie and Won-Hyuck Choi \\ Department of Aeronautical System Engineering, Hanseo University Graduate, \\ Chungcheongnam-do, 357-953, Korea
}

\begin{abstract}
An autopilot technology of the aircraft is considered important in all aircrafts as well as unmanned aircrafts. In order to perform the automatic aircraft flight along a predetermined path, the guidance law that induces the aircraft on the path is necessary. Generally, the guidance law mainly uses the LOS(Line-of-Sight) guidance law which uses the LOS vector. There is a problem including disturbance such as wind in the basic LOS guidance law. And the PID LOS guidance law has a disadvantage that PID LOS guidance law must redesign the control gain according to the current state or operating environment change of the aircraft. Therefore, in this paper, we propose aircraft guidance systems that consist of LOS guidance law and the fuzzy PID controller to follow the path more precisely. In addition, we compared the path following performance and feasibility of various existing researches of LOS guidance law using MATLAB/Simulink simulation.
\end{abstract}

Keywords: Path Following, LOS (Line-of-Sight), Guidance Law, Fuzzy Logic, PID Controller, Fuzzy PID

\section{Introduction}

In order to autopilot the aircraft performing a variety of missions along a predetermined path, it is necessary to have a guidance law. LOS guidance law is most commonly used to follow these flight paths. Basic LOS guidance law used the LOS from the current position to the final point of the aircraft. However, for this reason, there are two problems that include errors of the azimuth angle, and decline in the performance of path following as the disturbance such as wind and a change of the aircraft operating environment [1].

To solve these problems, a method for improving the performance of path following was studied by setting the virtual point above a straight line connecting the final point from the initial point into target point $[2,3]$. Also, in order to apply a PID controller to the Cross-Track-Error that is a vertical distance between the aircraft and the straight path, the LOS guidance law considering the vehicle kinematics [4] was suggested, and the research which is following the path precisely was conducted and a path information is forward feedbacked based on the PID controller [5]. In addition, fuzzy self-tuning PID LOS guidance law was studied to optimize the PID gain of the PID LOS guidance law and precisely follow the path [6].

In general, most of the LOS guidance law is designed through experimental methods. In this case, however, it is difficult to ensure the path following performance. Also, PID LOS guidance law requires a redesign of the PID gain in accordance with the non-linear change of aircraft operating environment [4].

In this paper, we apply the law by designing a fuzzy PID controller. Fuzzy controller is configured as an input variable of cross-track-error and approaching velocity, and an output variable of PID gain weight. Therefore, fuzzy PID LOS guidance law using the fuzzy PID controller makes it possible to follow the path although the aircraft operation 
environments are changed. And then, through a MATLAB/Simulink simulation, we confirmed that the proposed LOS guidance law is very precisely following the path as compared the basic LOS guidance law to the proposed LOS guidance law.

\section{Aircraft Guidance System}

The purposed aircraft guidance system is constituted to LOS guidance law and fuzzy PID controller. Section 2.1 explains LOS guidance law. Section 2.2 describes fuzzy PID controller.

\subsection{LOS Guidance Law}

The basic LOS guidance law is designed to the azimuth angle of an aircraft velocity $\left(\psi_{\mathrm{av}}\right)$ to converge to the azimuth angle of $\operatorname{LOS}\left(\psi_{\mathrm{LOS}}\right)$ connecting the aircraft location $\left(\mathrm{P}_{\mathrm{ac}}\right)$ and the final point $\left(\mathrm{P}_{\mathrm{f}}\right)$, as shown in Figure 1. Thus the azimuth angle of a LOS is used to command the heading angle of aircraft, as equation (1), (2).

$$
\begin{aligned}
& \psi_{L O S}=\tan ^{-1}\left(\left(x_{f}-x_{a c}\right) /\left(y_{f}-y_{a c}\right)\right) \\
& \psi_{c m d}=\psi_{L O S}
\end{aligned}
$$

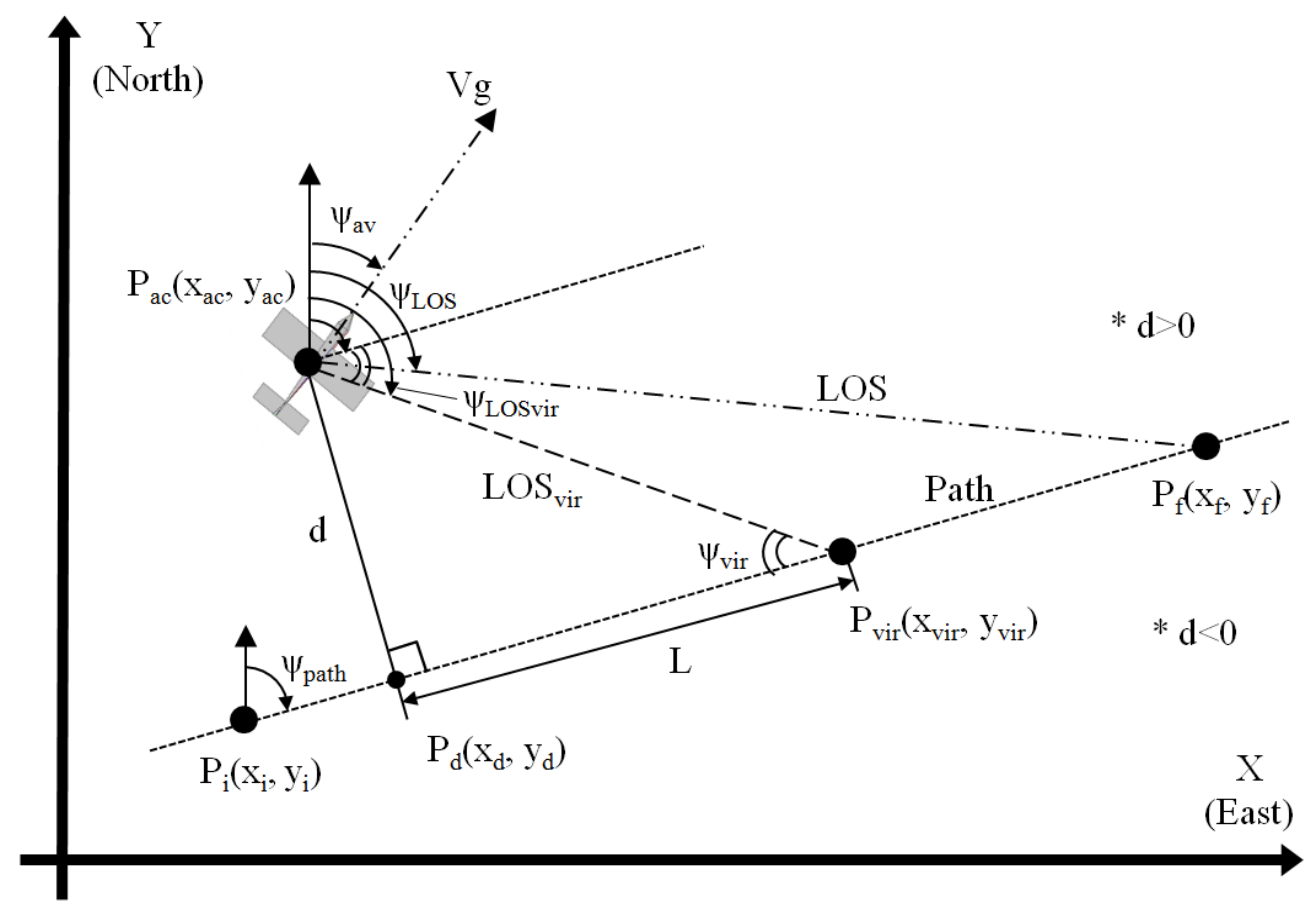

Figure 1. The Structure of LOS Guidance Laws

To follow path better than basic LOS guidance law, Calculate virtual point $\left(\mathrm{P}_{\text {vir }}\right)$ on the straight path to the final point from the initial point. And the command heading angle of aircraft is the azimuth angle of virtual LOS $\left(\psi_{\text {LOSvir }}\right)$ connecting the aircraft location and the virtual point, as equation (3), (4) [3].

$\psi_{\mathrm{LOSvir}}=\tan ^{-1}\left(\left(\mathrm{x}_{\mathrm{vir}}-\mathrm{x}_{\mathrm{ac}}\right) /\left(\mathrm{y}_{\mathrm{vir}}-\mathrm{y}_{\mathrm{ac}}\right)\right)$

$\psi_{\mathrm{cmd}}=\psi_{\mathrm{LOSvir}}$

The distance $\left(\operatorname{LOS}_{\text {vir }}\right)$ between the position of the aircraft $\left(\mathrm{P}_{\mathrm{ac}}\right)$ and the virtual position $\left(\mathrm{P}_{\mathrm{vi}}\right)$ is shown in equation (5). Cross-track-error(d) between the position of the $\operatorname{aircraft}\left(\mathrm{P}_{\mathrm{ac}}\right)$ and flight path is shown in equation (6). If the aircraft is positioned on the left side of the 
flight path, $d>0$. If on the right side, $d<0$. The distance $(\mathrm{L})$ between the position to perpendicular-projection $\left(\mathrm{P}_{\mathrm{d}}\right)$ and the virtual position $\left(\mathrm{P}_{\mathrm{vi}}\right)$ is shown in equation (7). The angle of virtual $\left(\psi_{\text {vir }}\right)$ between the aircraft position and the virtual point can be obtained by applying PID control to the cross-track-error, as shown in equation (8). Finally, the azimuth angle of the aircraft velocity and the command heading angle of the aircraft are each equation (9) and (10) [5].

$$
\begin{aligned}
& \operatorname{LOS}_{\text {vir }}=\sqrt{\left(\mathrm{x}_{\mathrm{vir}}-\mathrm{x}_{\mathrm{ac}}\right)^{2}+\left(\mathrm{y}_{\mathrm{vir}}-\mathrm{y}_{\mathrm{ac}}\right)^{2}} \\
& \mathrm{~d}=\operatorname{LOS}_{\mathrm{vir}} \sin \left(\Psi_{\text {vir }}\right) \\
& \mathrm{L}=\operatorname{LOS}_{\text {vir }} \cos \left(\psi_{\text {vir }}\right) \\
& \Psi_{\text {vir }}=\tan ^{-1}(\mathrm{~d} / \mathrm{L})=\tan ^{-1}\left(\left(\mathrm{k}_{\mathrm{p}} \mathrm{d}+\mathrm{k}_{\mathrm{i}} \int \mathrm{d}+\mathrm{k}_{\mathrm{d}} \dot{\mathrm{d}}\right) / \mathrm{L}\right) \\
& \Psi_{\text {path }}=\tan ^{-1}\left(\left(\mathrm{x}_{\mathrm{f}}-\mathrm{x}_{\mathrm{i}}\right) /\left(\mathrm{y}_{\mathrm{f}}-\mathrm{y}_{\mathrm{i}}\right)\right) \\
& \Psi_{\text {cmd }}=\Psi_{\text {path }}+\psi_{\text {vir }}
\end{aligned}
$$

\subsection{Fuzzy PID Controller}

Fuzzy PID controller provides better performance than a standalone PID controller and Fuzzy self-tuning PID controller. As shown in Figure 2, fuzzy PID controller is configured by adding a fuzzy controller and PID controller. Fuzzy controller is configured as an input variable of cross-track-error ' $d$ ' and approaching velocity ' $\dot{d}$ ', and an output variable of PID gain weight 'Q'. As in equation (11), fuzzy PID controller is multiplied by the weight ' $Q$ ' of the PID gain.

$\psi_{\text {vir }}=\tan ^{-1}(d / L)=\tan ^{-1}\left(\left(K_{P} d+K_{I} \int d+K_{D} \dot{d}\right) / L\right)$

where, $\mathrm{K}_{\mathrm{P}}=\mathrm{Q} * \mathrm{k}_{\mathrm{p}}, \mathrm{K}_{\mathrm{I}}=\mathrm{Q} * \mathrm{k}_{\mathrm{i}}, \mathrm{K}_{\mathrm{D}}=\mathrm{Q} * \mathrm{~K}_{\mathrm{d}}$

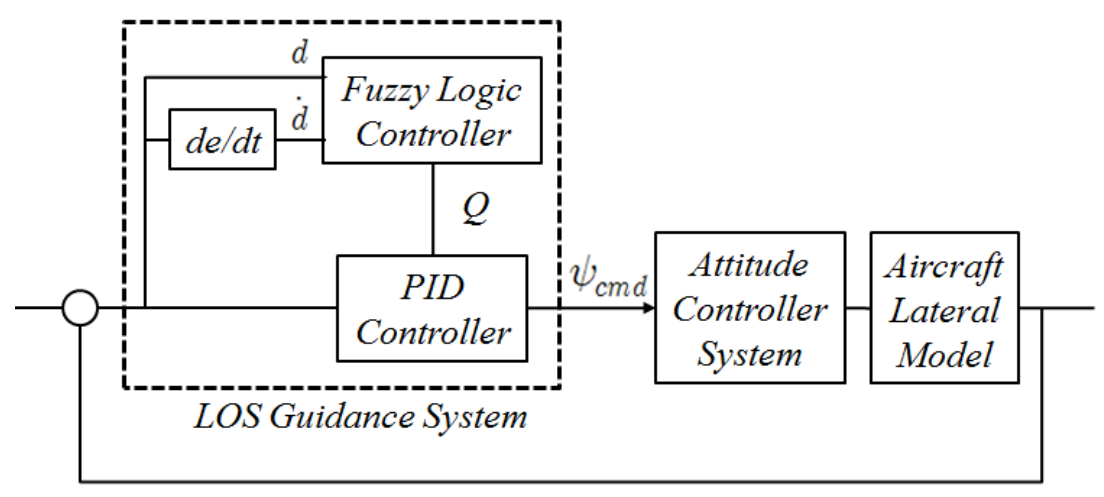

Figure 2. The Structure of Fuzzy PID Controller

The fuzzy sets for input variables consist of seven linguistic variables such as, NB (Negative Big), NM (Negative Middle), NS(Negative Small), ZE(Zero), PS(Positive Small), PM(Positive Middle), PB(Positive Big). And output variables consist of four linguistic variables such as, VS (Very Small), S(Small), M(Middle), B(Big). Range of the cross-track-error' $\mathrm{d}$ ' is $-350 \mathrm{~m} \sim+350 \mathrm{~m}$, the approaching velocity ' $\dot{\mathrm{d}}$ ' is $-55 \mathrm{~m} / \mathrm{s} \sim+55 \mathrm{~m} / \mathrm{s}$ and weight ' $Q$ ' is $0 \sim 1$. Membership functions of inputs ' $d$ ', ' $d$ ' and output ' $Q$ ' are shown in Figure 3. 


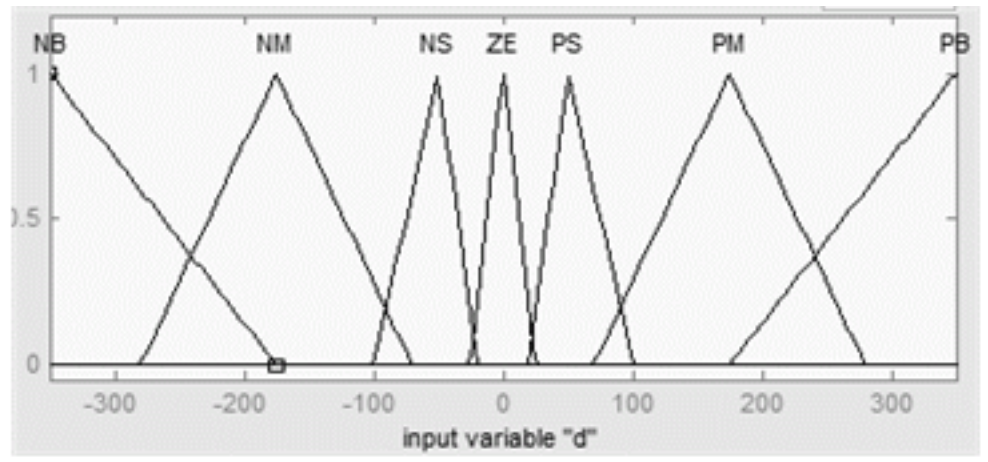

$d$

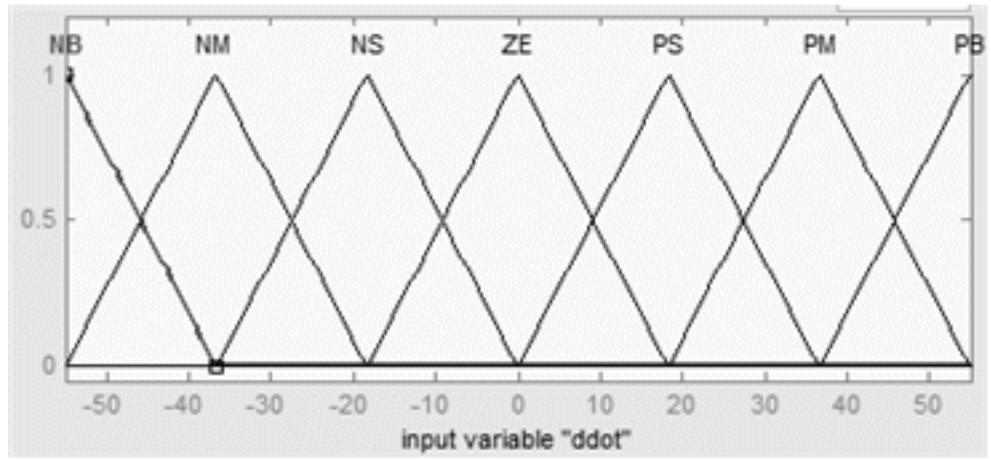

$\dot{d}$

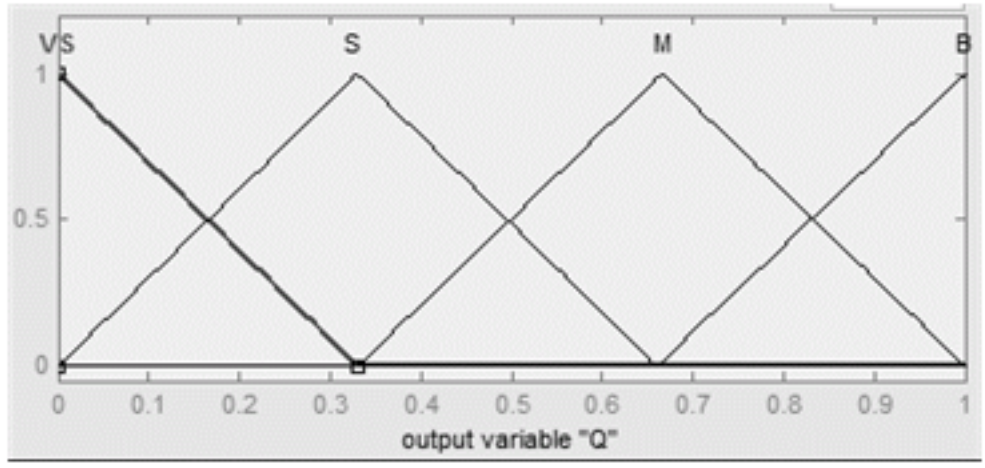

Q

Figure 3. The Membership Functions of Fuzzy PID Controller

The fuzzy rules have 49 ways, shown in Table 1 . Figure 4 is a three-dimensional surface of the output Q.

Table 1. Fuzzy Rule Table

\begin{tabular}{|c|c|c|c|c|c|c|c|}
\hline d & NB & NM & NS & ZE & PS & PM & PB \\
\hline NB & B & B & S & B & M & B & B \\
\hline NM & B & B & S & M & M & M & B \\
\hline NS & B & B & S & S & M & B & B \\
\hline ZE & B & B & M & VS & M & B & B \\
\hline
\end{tabular}




\begin{tabular}{|c|c|c|c|c|c|c|c|}
\hline PS & B & B & B & S & B & B & B \\
\hline PM & B & M & M & M & S & B & B \\
\hline PB & B & B & M & B & S & B & B \\
\hline
\end{tabular}

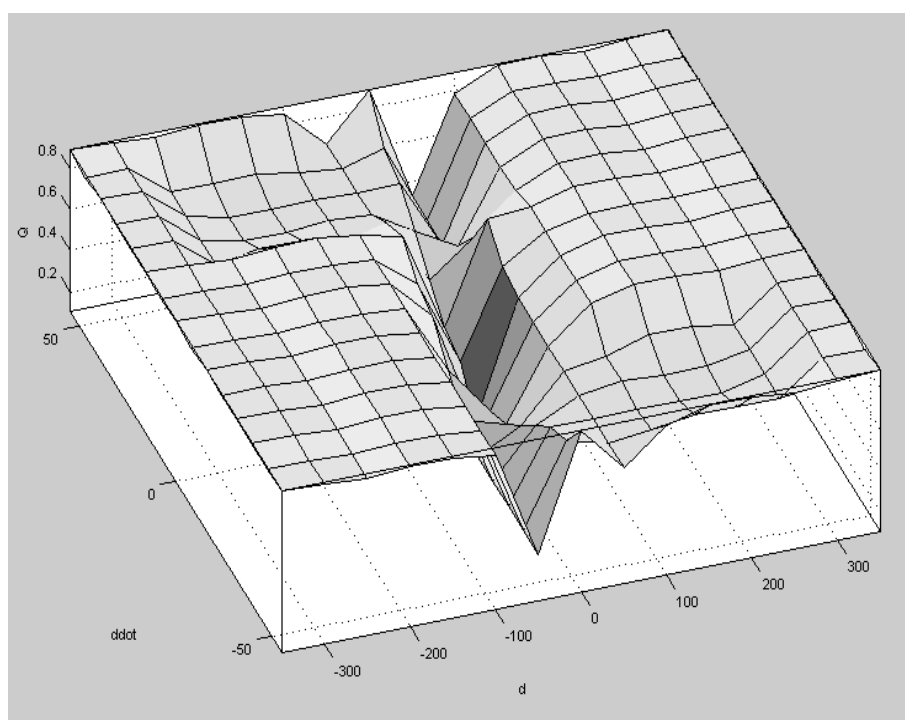

Figure 4. The Surface of Output $Q$

\section{Simulation}

\subsection{Aircraft Model}

In this paper, we compared the fuzzy PID LOS guidance law with conventional guidance law using MATLAB/Simulink simulation. In the simulation, the aircraft is a linear model of general aviation aircraft NAVION. Geometry and aerodynamic characteristics of the NAVIO are shown in Table 2 and Table 3. Using the Geometry and aerodynamic characteristics was determined longitudinal and lateral linear state equation of the NAVION aircraft. The longitudinal equation and the lateral equation are each equation (12) and equation (13) [7].

Table 2. NAVION Geometry Characteristics

\begin{tabular}{|c|c|c|c|c|}
\hline W(weight) & S(area) & $\mathbf{b}$ (wing span) & $\overline{\mathbf{c}}$ (mean chord) & $\mathbf{I}_{\mathbf{X X}}$ \\
\hline $2750 \mathrm{lbs}$ & $184 \mathrm{ft}$ & $33.4 \mathrm{ft}$ & $5.7 \mathrm{ft}$ & $1048 \mathrm{slug} \cdot \mathrm{ft}^{2}$ \\
\hline $\mathbf{I}_{\mathbf{Y Y}}$ & $\mathbf{I}_{\mathrm{ZZ}}$ & $\mathbf{I}_{\mathbf{X Y}}$ & $\mathbf{H}_{\mathbf{0}}($ altitude $)$ & $\mathbf{U}_{\mathbf{0}}(\mathbf{s p e e d})$ \\
\hline $3000 \mathrm{slug} \cdot \mathrm{ft}^{2}$ & $3530 \mathrm{slug} \cdot \mathrm{ft}^{2}$ & 0 & $328 \mathrm{ft}(100 \mathrm{~m})$ & $176 \mathrm{ft} / \mathrm{s}$ \\
\hline
\end{tabular}


Table 3. NAVION Aerodynamic Characteristics

\begin{tabular}{|c|c|c|c|c|c|c|c|}
\hline \multicolumn{5}{|c|}{ Longitudinal } & \multicolumn{5}{c|}{ Lateral } \\
\hline $\mathrm{C}_{\mathrm{L}}$ & 0.41 & $\mathrm{C}_{\mathrm{L}_{\mathrm{q}}}$ & 3.8 & $\mathrm{C}_{\mathrm{y}_{\beta}}$ & -0.564 & $\mathrm{C}_{\mathrm{l}_{\delta \mathrm{a}}}$ & 0.134 \\
\hline $\mathrm{C}_{\mathrm{L}}$ & 0.05 & $\mathrm{C}_{\mathrm{m}_{\alpha}}$ & -9.96 & $\mathrm{C}_{\mathrm{l}_{\beta}}$ & -0.074 & $\mathrm{C}_{\mathrm{n}_{\delta \mathrm{a}}}$ & -0.0035 \\
\hline $\mathrm{C}_{\mathrm{L}_{\alpha}}$ & 4.44 & $\mathrm{C}_{\mathrm{L}_{\mathrm{M}}}$ & 0.0 & $\mathrm{C}_{\mathrm{n}_{\beta}}$ & 0.071 & $\mathrm{C}_{\mathrm{y}_{\delta \mathrm{r}}}$ & 0.157 \\
\hline $\mathrm{C}_{\mathrm{D}_{\alpha}}$ & 0.33 & $\mathrm{C}_{\mathrm{D}_{\mathrm{M}}}$ & 0.0 & $\mathrm{C}_{\mathrm{l}_{\mathrm{p}}}$ & -0.410 & $\mathrm{C}_{\mathrm{l}_{\delta \mathrm{r}}}$ & 0.107 \\
\hline $\mathrm{C}_{\mathrm{m}_{\alpha}}$ & -0.683 & $\mathrm{C}_{\mathrm{m}_{\mathrm{M}}}$ & 0.0 & $\mathrm{C}_{\mathrm{n}_{\mathrm{p}}}$ & -0.0575 & $\mathrm{C}_{\mathrm{n}_{\delta \mathrm{r}}}$ & -0.027 \\
\hline $\mathrm{C}_{\mathrm{L}_{\dot{\alpha}}}$ & 0.0 & $\mathrm{C}_{\mathrm{L}_{\delta \mathrm{e}}}$ & 0.355 & $\mathrm{C}_{\mathrm{l}_{\mathrm{r}}}$ & 0.107 & \multicolumn{2}{|c|}{ unit } \\
\hline $\mathrm{C}_{\mathrm{m}_{\dot{\alpha}}}$ & -4.36 & $\mathrm{C}_{\mathrm{m}_{\delta \mathrm{e}}}$ & -0.923 & $\mathrm{C}_{\mathrm{n}_{\mathrm{r}}}$ & -0.125 & \multicolumn{2}{|c|}{$1 / \mathrm{rad}$} \\
\hline
\end{tabular}

$\left[\begin{array}{c}\dot{\mathrm{u}} \\ \dot{\mathrm{w}} \\ \mathrm{q} \\ \dot{\theta}\end{array}\right]=\left[\begin{array}{cccc}-0.0451 & 0.0361 & 0 & -32.2 \\ -0.3695 & -2.0235 & 176 & 0 \\ 0.0019 & -0.0395 & -2.9845 & 0 \\ 0 & 0 & 1 & 0\end{array}\right]\left[\begin{array}{c}\mathrm{u} \\ \mathrm{w} \\ \mathrm{q} \\ \theta\end{array}\right]+\left[\begin{array}{c}0 \\ -28.1575 \\ -11.7341 \\ 0\end{array}\right]\left[\delta_{\mathrm{e}}\right]$

$y=\left[\begin{array}{llll}1 & 0 & 0 & 0 \\ 0 & 1 & 0 & 0 \\ 0 & 0 & 1 & 0 \\ 0 & 0 & 0 & 1\end{array}\right]\left[\begin{array}{c}\mathrm{u} \\ \mathrm{w} \\ \mathrm{q} \\ \theta\end{array}\right]+\left[\begin{array}{l}0 \\ 0 \\ 0 \\ 0\end{array}\right]\left[\delta_{\mathrm{e}}\right]$

$\left[\begin{array}{c}\dot{\beta} \\ \dot{\mathrm{p}} \\ \dot{\mathrm{r}} \\ \dot{\phi}\end{array}\right]=\left[\begin{array}{cccc}-0.2542 & 0 & -1 & 0.183 \\ -15.9757 & -8.3988 & 2.1919 & 0 \\ 4.5506 & -0.3497 & -0.7602 & 0 \\ 0 & 1 & 0 & 0\end{array}\right]\left[\begin{array}{c}\beta \\ \mathrm{p} \\ \mathrm{r} \\ \phi\end{array}\right]+\left[\begin{array}{c}0 \\ -28.9289 \\ -0.2243 \\ 0\end{array}\right]\left[\delta_{\mathrm{a}}\right]$

$\mathrm{y}=\left[\begin{array}{llll}1 & 0 & 0 & 0 \\ 0 & 1 & 0 & 0 \\ 0 & 0 & 1 & 0 \\ 0 & 0 & 0 & 1\end{array}\right]\left[\begin{array}{l}\beta \\ \mathrm{p} \\ \mathrm{r} \\ \phi\end{array}\right]+\left[\begin{array}{l}0 \\ 0 \\ 0 \\ 0\end{array}\right]\left[\delta_{\mathrm{a}}\right]$

\subsection{MATLAB/Simulink Simulation Model}

Aircraft guidance simulation model is configured using MATLAB/Simulink as shown in the Figure 5. The simulation model is constructed by guidance system, attitude control system and aircraft model. The guidance system is constructed by path manager, LOS guidance law, and the attitude control system. 


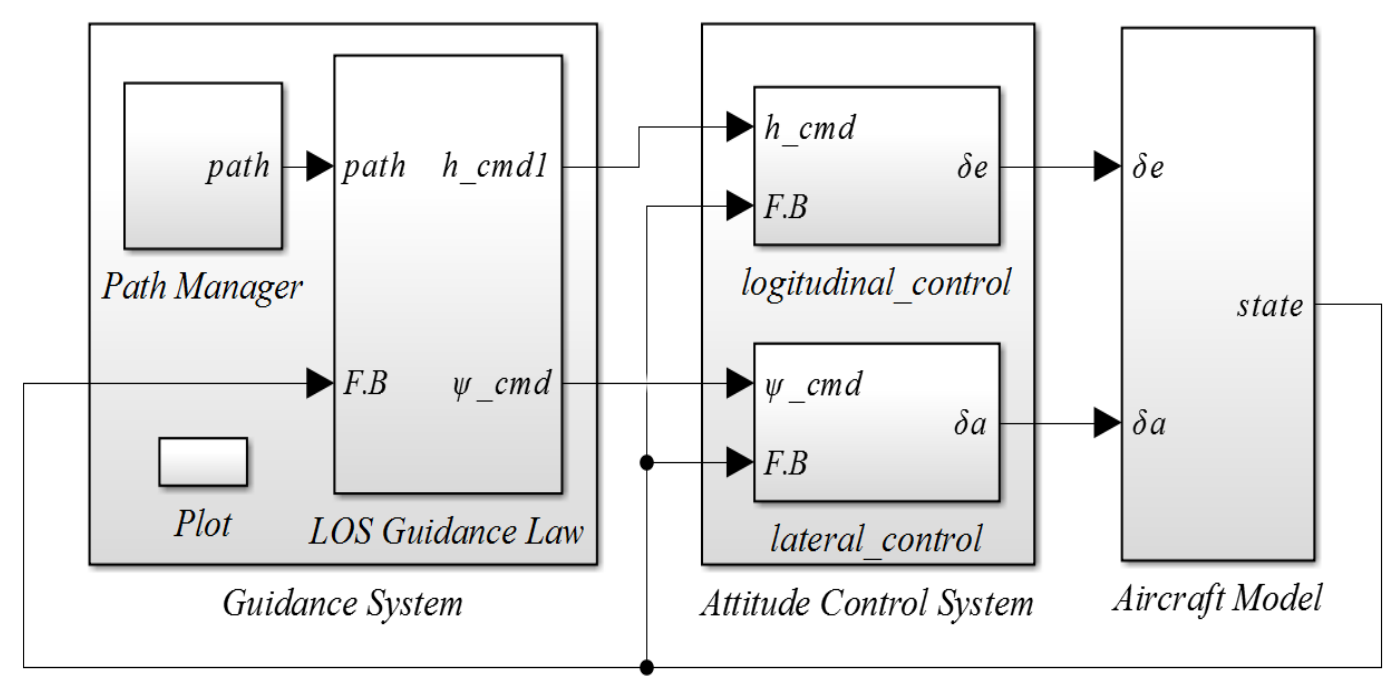

Figure 5. Aircraft Guidance Simulation MATLAB/Simulink Model

The path manager produces the complete path of the flight simulation so as to pass multiple waypoints, as shown in Figure 6.

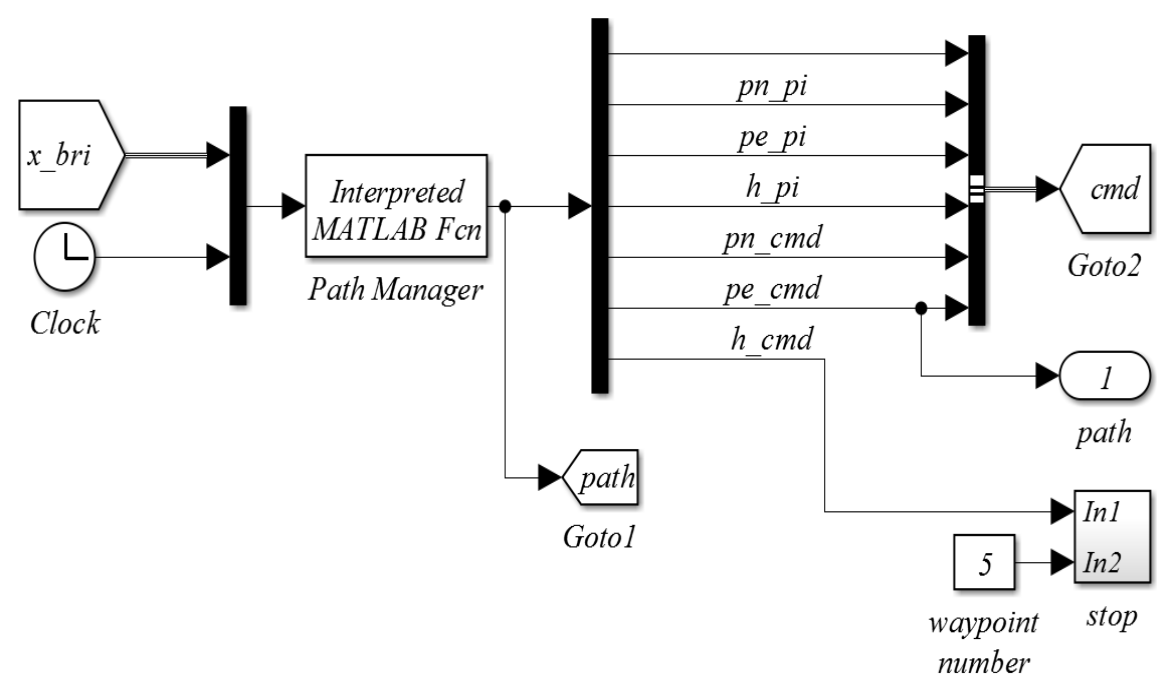

Figure 6. Path Manager MATLAB/Simulink Model

LOS guidance law consists of a variable calculation, fuzzy controller and the PID controller, as shown in Figure 7. In this paper, the gains of PID controller are set to $\mathrm{kp}=8.9401, \mathrm{ki}=0.007304, \mathrm{kd}=16.0369$. 

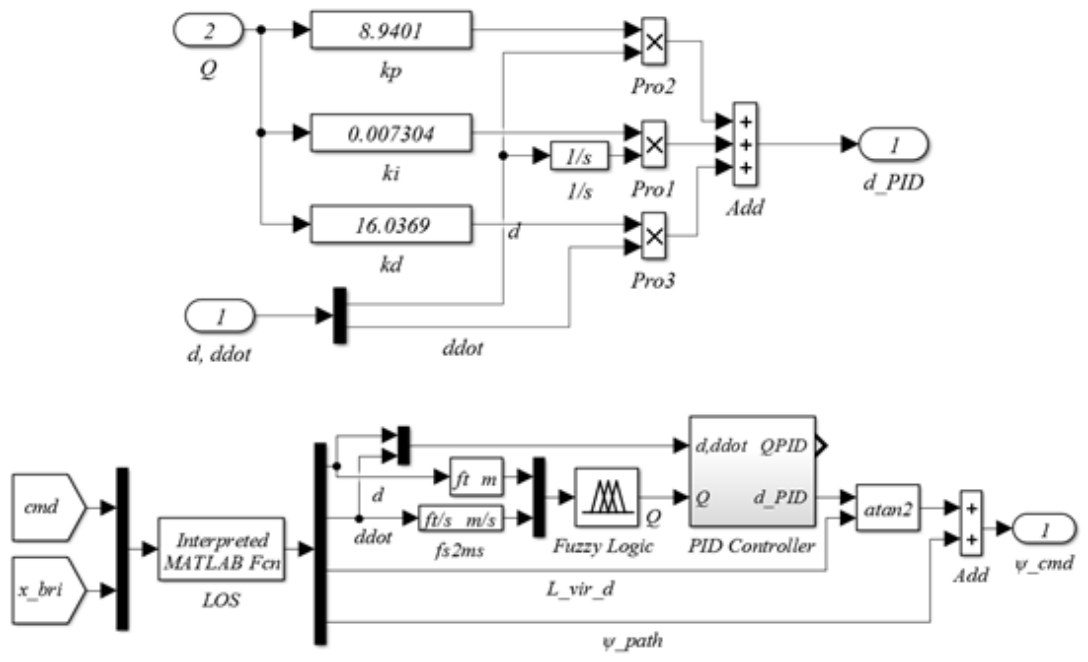

Figure 7. Fuzzy PID LOS Guidance Law MATLAB/Simulink Model

As shown in Figure 8, longitudinal control is receiving an altitude command, feedback altitude, pitch angle, the pitch angular velocity from the aircraft models, and outputting to angle of elevator control surface. It performs the longitudinal attitude control and altitude hold control using each the PI and PID controller.

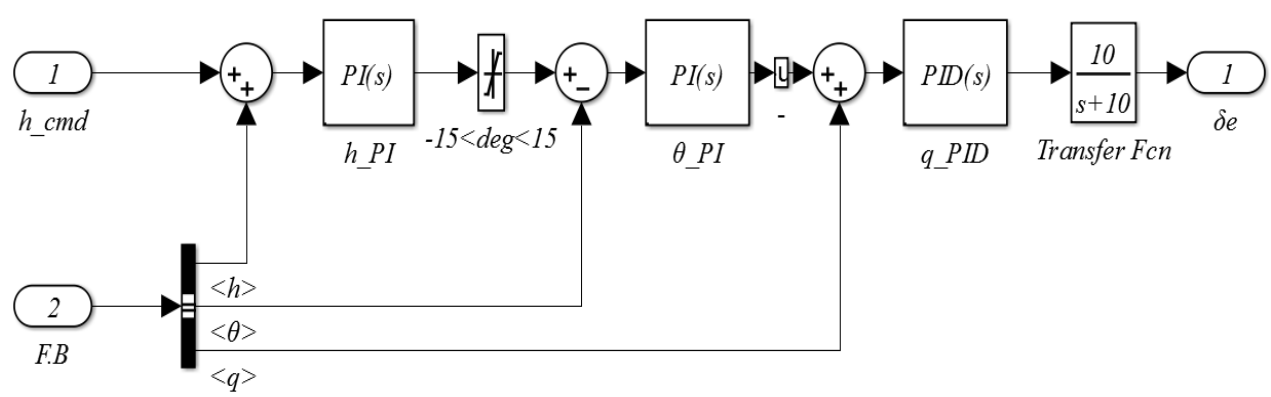

Figure 8. Longitudinal Control MATLAB/Simulink Model

As shown in Figure 9, lateral control is receiving a direction angle of aircraft command, feedback direction angle of aircraft, roll angle, the roll angular velocity from the aircraft models, and outputting to angle of aileron control surface. It performs the lateral attitude control and direction angle control using each the PI and PID controller.

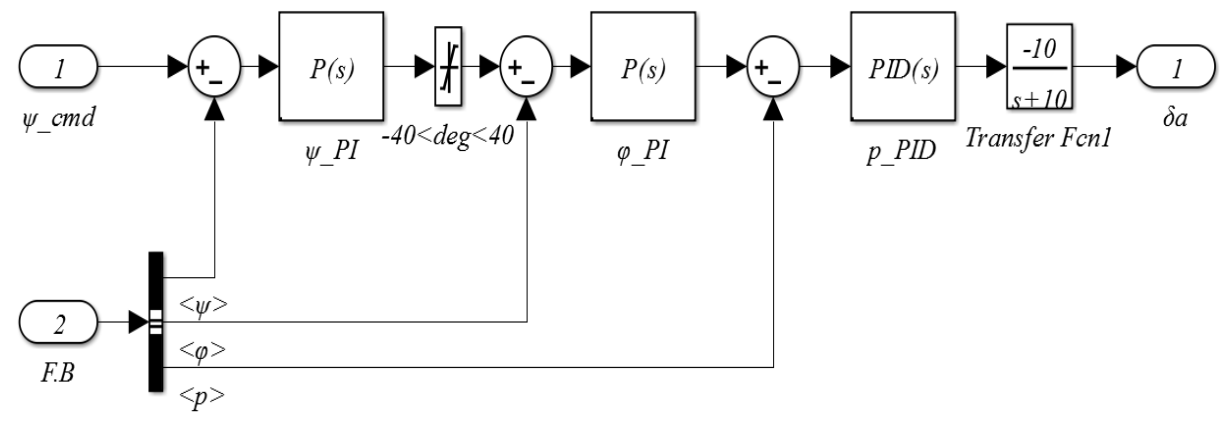

Figure 9. Lateral Control MATLAB/Simulink Model

Aircraft model to calculate the variables in a linear equation of state indicates the current state aircraft, as shown in Figure 10. 


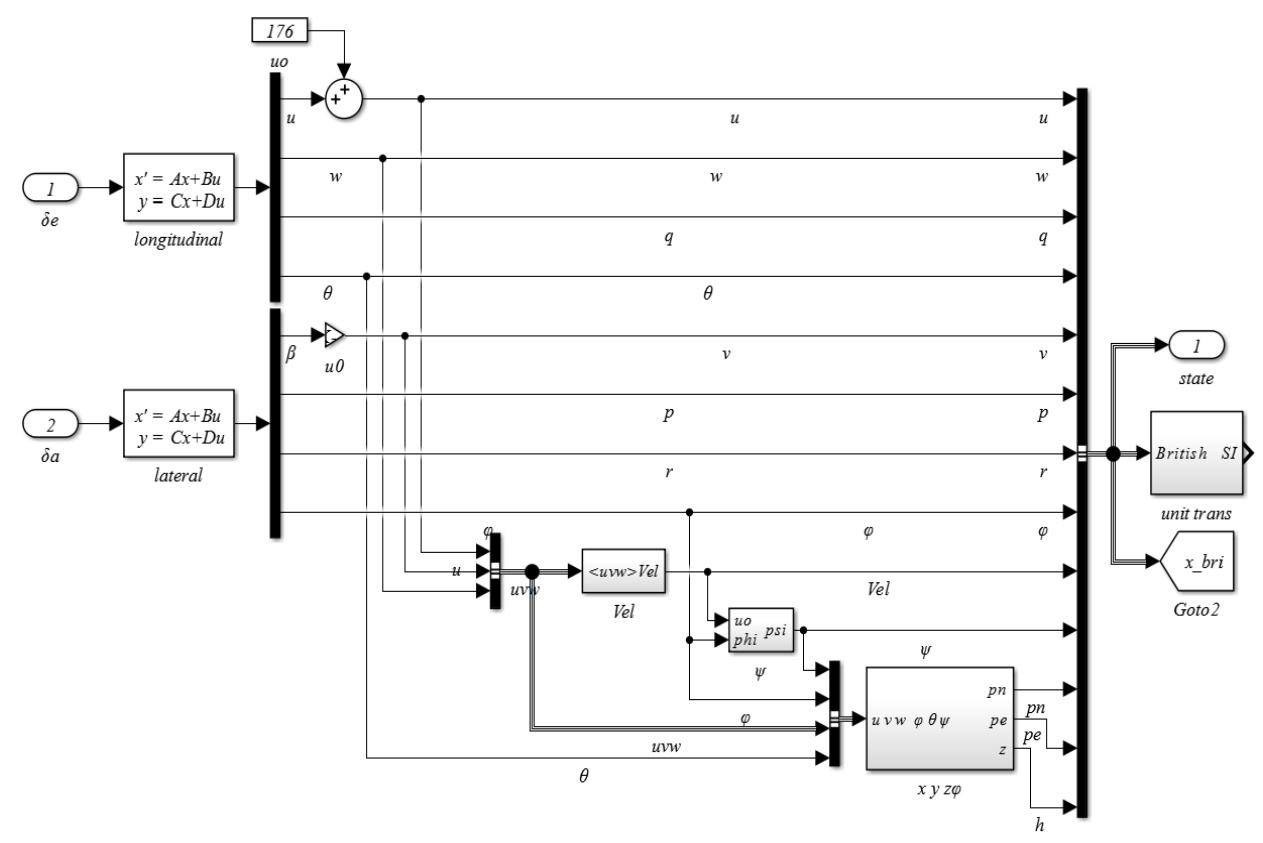

Figure 10. Aircraft Model MATLAB/Simulink Model

\subsection{Path Following Simulation}

Among the various LOS guidance laws, the simulation was compared with the basic LOS, modified LOS, PID LOS and fuzzy PID LOS guidance law. Also, the PID LOS guidance law is compared with fuzzy PID LOS guidance law with respect to the path of generated randomly, yaw angle, roll angle, cross-track-error and arrival time.

The first simulation was performed by creating a path of flight from an initial point $(0 \mathrm{~m}, 0 \mathrm{~m})$ to a target point $(2000 \mathrm{~m}, 0 \mathrm{~m})$, as shown in Figure 11 . PID and fuzzy PID LOS guidance law is excellent in following performance to approach path more than common LOS and modified LOS guidance law. And fuzzy PID LOS guidance law is converged more quickly to a target point by $1 \sim 2 \mathrm{sec}$ than PID LOS guidance law. It is because the overshoot occurs in the controller with PID LOS guidance law.

The second simulation was performed by creating a path of flight from any waypoint. Any waypoint is totally 6 points, and WPO $(0,0) \mathrm{m}$, WP1 $(0,500) \mathrm{m}$, WP2 $(-500,2000) \mathrm{m}$, WP3 $(1000,3000) \mathrm{m}$, WP4 $(2000,1500) \mathrm{m}$, WP5 $(2100,0) \mathrm{m}$, as shown in Figure 12. Figure 13 shows a yaw angle, roll angle, cross-track-error and arrival time in flight on path. Like the first simulation, fuzzy PID LOS guidance law is a stable attitude of aircraft because oscillation and overshoot of roll angle do not occur. Also, since the cross-track-error also does not occur in overshoot and oscillation, the aircraft arrived more quickly at the target position, and has excellent tracking performance of the whole path, as shown Figure 12, 13.

Fuzzy PID LOS Guidance Law using the fuzzy logic is converged to constant on all paths due to changes of the control gain by the cross-track-error and approach speed. For the superior path following performance of the PID LOS guidance law, it must be designed to control the gain through the repeated experiments on all paths. Since flying paths have non-linear characteristics, Fuzzy PID controller showed more excellent control performance than PID controller in a non-linear characteristic. 

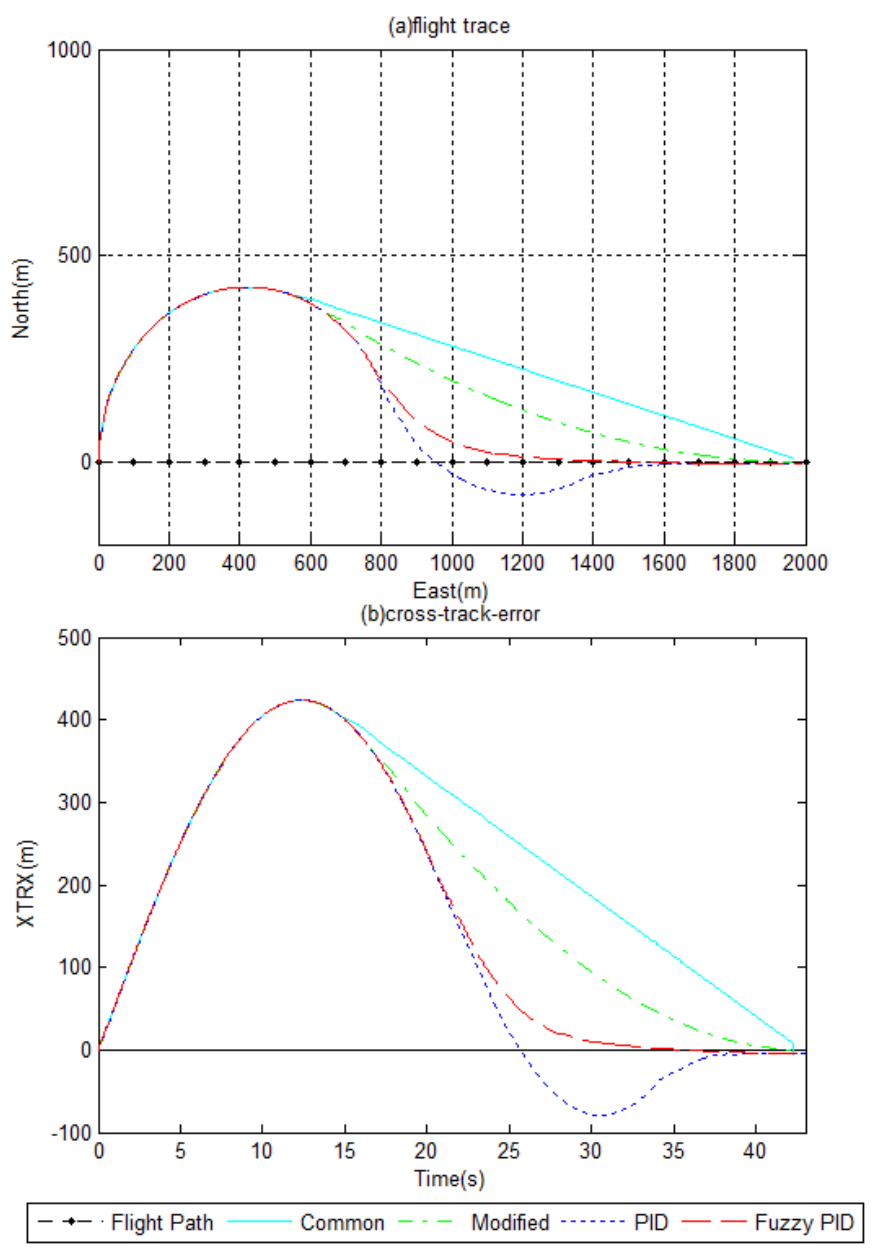

Figure 11. Aircraft Flight Trace and Cross-Track-Error

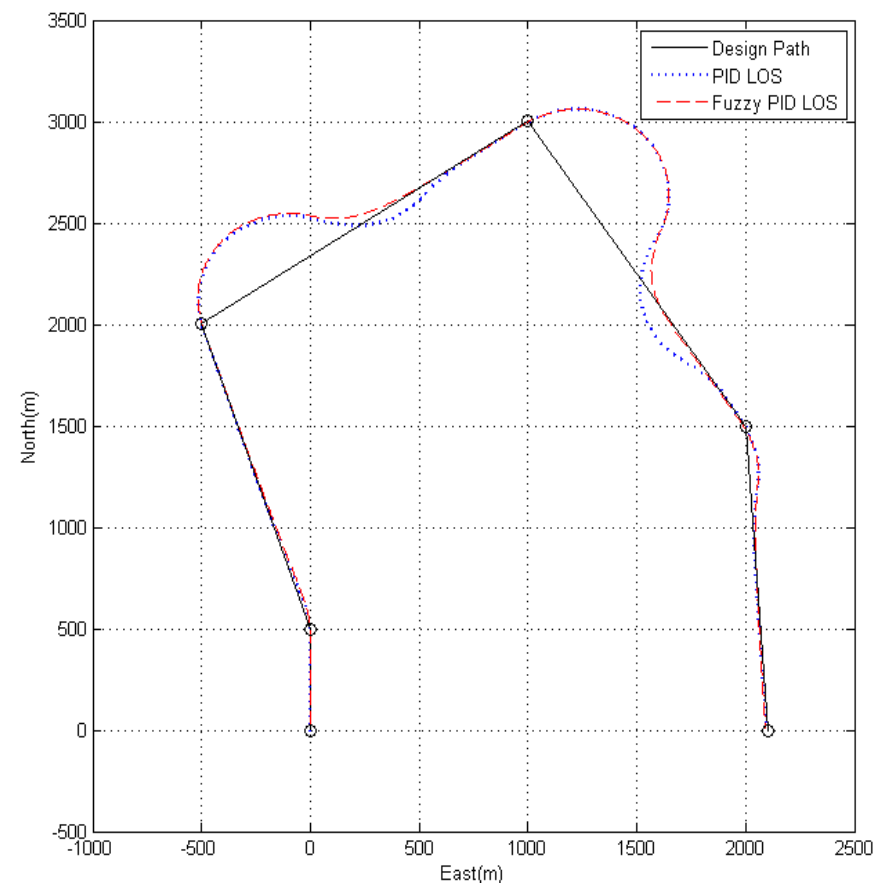

Figure 12. Aircraft Flight Trace on Flight Path 

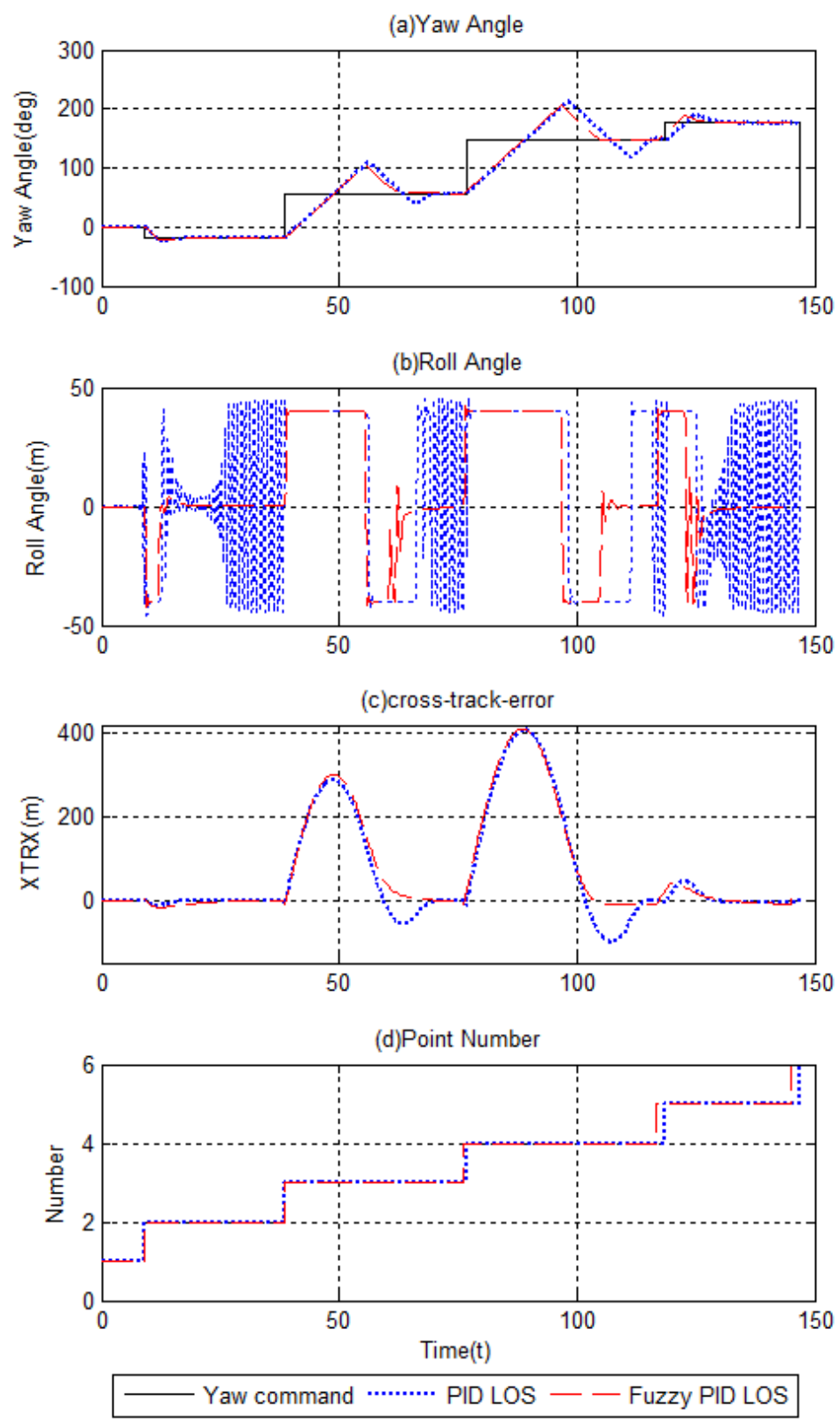

Figure 13. Aircraft Flight State on Flight Path

\section{Conclusion}

In this paper, to simulate the LOS guidance law, MATLAB/Simulink is used. It was derived from the common LOS, modified LOS, and PID LOS guidance law of existing research. Also, we designed a fuzzy PID LOS guidance law to follow path from the nonlinear environment by applying the fuzzy controller. Control gain of fuzzy PID controller is determined according to the cross-track-error and approach speed. And it follows the path by generating a command direction angle of the aircraft. Simulations were performed to follow the non-linear flying path. Fuzzy PID LOS guidance law does not have the steady-state errors. Oscillation and overshoot do not occur. Therefore, we demonstrated that the fuzzy PID controller is performed better than in previous studies. As a result, the proposed LOS method is expected to use a mission which has a variety of paths. In addition, it is expected to be applied to the aircraft to perform a variety of missions. 


\section{Acknowledgement}

This paper is a revised and expanded version of a paper entitled 'Advanced Science and Technology Letters' presented at 'The 5th International Conference on Information Science and Industrial Applications, Harbin, China, August 19-20'.

\section{References}

[1] Y. Lee, "A Study on the Autopilot System Design for a Flying Type Mico Aerial Vehicle with Pat Generation and Guidance Law", Graduate School of Korea Aerospace University, (2015).

[2] T. I. Fossen, Editor, "Marine Control System. Marine Cybernetics", Trondheim, Norway, (2002).

[3] S. Lee, H. Choi, J. Lee and J. Chang, "Generalization and Application of LOS Guidance Law for UAV", Proceedings of the Korean Society for Aeronautical and Space Sciences Fall Meeting, Pyeongchang, Korea, (2011).

[4] D. You and H. Shim, "Design a Path Following Line-of-Sight Guidance Law Based on Vehicle Kinematics", Journal of The Korean Society for Aeronautical and Space Sciences, vol. 40, no. 6, (2002), pp. 506-514.

[5] I. Rhee, S. Park and C. Ryoo, "A Tight Path Following Algorithm of an UAS Based on PID Control”, Proceedings of SICE Annual Conference, Taipei, Taiwan, (2010) Aug 18-21.

[6] S. H. Park, W. H. Choi and M. S. Jie, "A LOS Guidance Law for Path Following of an Aircraft Using Fuzzy Self-Tuning PID Controller", Proceedings of the 5th International Conference on Information Science and Industrial Applications, Harbin, China, (2016).

[7] R. C. Nelson, Editor, "Flight Stability and Automatic Control", McGraw-Hill, New York, (1998).

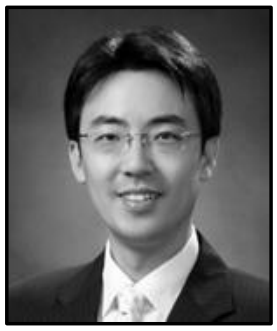

Min-Seok Jie, he received the Ph.D. degree in avionics from Korea Aerospace University, Korea. He was a Researcher of Intelligent Robot Research Center at Korea Institute of Science and Technology from 2007 to 2008. And he was a visiting professor at Purdue University from 2015 to 2016. Currently, he is Professor of avionics at Hanseo University, Korea, where he has been since 2008. His present research interests include robust control, robot vision, UAV.

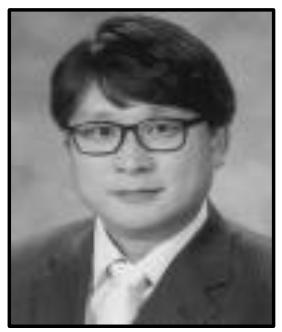

Won-Hyuck Choi (Corresponding Author), he received the Ph.D. degree in avionics from Korea Aerospace University, Korea. He was a Professor of smart network at Doowon Technical University College, Korea. Currently, he is Professor of avionics at Hanseo University, Korea, where he has been since 2014. His present research interests include embedded system, home network 